\title{
Viability of Bull Spermatozoa Collected from the Epididymis Stored at $18-20^{\circ} \mathrm{C}$
}

\author{
Melina Andrea Formighieri Bertol ${ }^{1 *}$, Romildo Romualdo Weiss ${ }^{1}$, Vanete Thomaz-Soccol ${ }^{1}$, \\ Luiz Ernandes Kozicki ${ }^{2}$, Aline Silva Fujita ${ }^{3}$, Renata Azevedo de Abreu ${ }^{1}$ and Kerriel \\ Thandile Green ${ }^{4}$ \\ ${ }^{I}$ Programa de Pós-Graduação em Engenharia de Bioprocessos e Biotecnologia; Setor de Tecnologia; Universidade \\ Federal do Paraná; Curitiba - PR - Brasil. ${ }^{2}$ Centro de Ciências Agrárias e Ambientais; Pontifícia Universidade \\ Católica do Paraná; Curitiba - PR - Brasil. ${ }^{3}$ Médicas Veterinárias Autônomas. ${ }^{4}$ Centro de Ciências Agrárias; \\ Universidade Estadual de Londrina; Londrina - PR - Brasil
}

\begin{abstract}
The aim of this study was to evaluate the viability of bull spermatozoa collected from the cauda epididymis stored at $18-20^{\circ} \mathrm{C}$, which were compared with semen collected by electro-ejaculation method and preserved at $5^{\circ} \mathrm{C}$. Ten pairs of testes from Tabapuã bulls were removed by orchiectomy and stored for 6 (G6), 12 (G12), 18 (G18), 24 (G24) and $30(\mathrm{G} 30) \mathrm{h}$ at room temperature $\left(18-20^{\circ} \mathrm{C}\right)$. Seven days before orchiectomy, semen was collected by electroejaculation method. The sperm parameters evaluated were: sperm motility, vigor, concentration, morphology and acrosome defects. Sperm motility declined $(p<0.05)$ when spermatozoa were stored for $30 \mathrm{~h}$ in the epididymis. The spermatozoa from the epididymis showed lower sperm motility than that of spermatozoa collected via electroejaculation. There was a little expressive decrease in sperm vigor and increased in morphological defects with storage time, but the acrosome integrity was not affected. Cold storage $\left(5^{\circ} \mathrm{C}\right)$ maintained sperm viable for 15 to 40.8 $h$. Thus, it was possible to recover viable sperm with $41.25 \%$ of motility from the cauda epididymis stored at room temperature of $18-20^{\circ} \mathrm{C}$ for $30 \mathrm{~h}$. There were differences between the ejaculated and epididymal sperm for the bulls and the conservation at $5^{\circ} \mathrm{C}$ allowed short-term preservation of the gametes.
\end{abstract}

Key words: Bull, Epididymis, Orchiectomy, Sperm, Room temperature, Viability

\section{INTRODUCTION}

The unexpected losses of genetically valuable animals, as well as the difficulty to collecting semen from wild species lead to an increase in the use of artificial reproductive techniques, since it proves to be one of the unique possibilities to preserve the genetic material of these animals (Kaabi et al. 2003). The recovery and cryopreservation of spermatozoa from the epididymides of deceased animals (recovery postmortem) is a viable option in maintaining their germplasm available for future use (Tittarelli et al. 2006). Studies have shown the efficacy and potential of epididymal spermatozoa to result in fertilization in vitro and in vivo by using these spermatozoa in artificial insemination, in vitro fertilization of embryos and intracytoplasmic sperm injection with satisfactory results (SantiagoMoreno et al. 2006; Martins et al. 2007; Costa et al. 2011; Monteiro et al. 2011; Ringleb et al. 2011).

The cauda epididymis in the mammals is responsible for the storage of viable spermatozoa

*Author for correspondence: melbertol@ hotmail.com 
until the moment of ejaculation and proportions a favorable environment for the preservation of its fertilization capacity for several weeks (Jones 2004). However, it is known that after the death the gametes in the body of animals, there is rapid degeneration, and the conditions such as time and temperature to which the epididymis is exposed influence directly the sperm viability (Kaabi et al. 2003).

Ideally, the collection of gametes should be done immediately following the death of the animal; however, this is usually not always possible. In countries of continental dimensions, the harvesting and preservation of epididymal spermatozoa immediately post-mortem proves to be difficult due to the lack of technicians, or equipments (Martins et al. 2009). In tropical countries, animals are exposed to an average temperature of $20^{\circ} \mathrm{C}$. Studies in various species have evaluated the durability of spermatozoa in the cauda epididymides maintained at room temperature about $20^{\circ} \mathrm{C}$ (Garde et al. 1998; Muradás et al. 2006; Weiss et al. 2008; Toyonaga et al. 2011). However, in the bovine species, there are few reports of the recovery of male gametes under these conditions.

Others studies in several species have demonstrated that when the epididymides are maintained cooled immediately after the death, the spermatozoa viability is maintained for long periods (Martinez-Pastor et al. 2005; Soler et al. 2005; Tittareli et al. 2006; Martins et al. 2009). However, in a realistic view of the extensive cattle production system in Brazil, when the carcass of the animal has been found, many hours have passed since it has been exposed to atmospheric temperature.

Several sperm collection methods are employed to harvest the epididymal sperm and vary according to the animal species, the size of the epididymis and the operator. In bulls, the most appropriate method is retrograde flush. This method provides good quality sperm samples free of the cells and blood tissue contaminants (Turri et al. 2011). The objectives of this study were to determine the viability time of spermatozoa stored in the cauda epididymis of Tabapuã bulls (Bos taurus indicus) at room temperature of $18-20^{\circ} \mathrm{C}$ to compare the sperm parameters (motility, vigor, morphological defects in spermatozoa and acrosome defects) of spermatozoa collected from the caudal epididymal with those obtained by electro-ejaculation method, as well as assessing the resistance time of the spermatozoa when stored at $5^{\circ} \mathrm{C}$ post-collection.

\section{MATERIALS AND METHODS}

\section{Location and Animals}

The experiment was conducted on a farm located

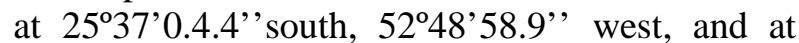
$505 \mathrm{~m}$ above sea level, in the south-western province in the state of Paraná, Brazil. Ten purebred Tabapuã bulls (Bos taurus indicus), with an average age and weight of 63 months and 573 $\mathrm{kg}$ respectively were selected. The animals were reared in an extensive grazing system of star grass (Cynodon spp), and divided in paddocks with access to shelter, water and mineral salt (Fosbovi 30, Tortuga, São Paulo, Brazil) ad libitum throughout the experiment.

\section{Semen Collection by Electro-ejaculation Method}

Two ejaculates were collected by electroejaculation method from each bull within a threeday interval to select the animals and establish sperm parameters. Seven days subsequently to this procedure, another semen sample was collected to correspond to the electro-ejaculated semen. The preputial orifices of the bulls were cleaned by introducing a flexible tube with sterile saline solution warmed at $37^{\circ} \mathrm{C}$ before each sample collection.

\section{Sperm Evaluation}

Immediately after the collection, the semen was diluted with a skim milk-based diluent (BotuTurbo $^{\mathrm{TM}}$, Botupharma, Botucatu, Brazil) in a proportion of $1: 1(\mathrm{v} / \mathrm{v})$ and was maintained at a temperature of $29^{\circ} \mathrm{C}$ in water bath for an hour until stabilized. The semen samples of each group were evaluated based on the following parameters: motility (0-100\% sperm motility); vigor (0-5; $0=$ absence of progressive movement and $5=$ vigorous and fast movement) for subjective analyses determined optically under a microscope with two different evaluators and applying an average, and also sperm concentration, morphology and acrosome defects. The sperm concentration was determined using a hemocytometer 1:100 dilution (semen: buffered saline-formalin solution). The results were reported as the number of cells/ml and multiplying by the total volume of the sample resulted in the 
total number of spermatozoa. To evaluate the morphological characteristics of the spermatozoa, an aliquot of $20 \mu \mathrm{L}$ of semen was diluted in 2.0 $\mathrm{mL}$ of buffered formalin-saline solution. The aliquots were placed in $1.5 \mathrm{~mL}$ ampoules and stored at $4-5^{\circ} \mathrm{C}$ for subsequent analysis. The evaluation of sperm morphology and acrosome integrity was analyzed using a phase contrast microscope (Olympus BX41, Tokyo, Japan) at x1000 magnification and 200 sperm cells were counted per slide (Blom 1973).

\section{Bilateral Orchiectomy}

Seven days after the collection of the electroejaculated semen, the bulls were castrated. After adequately restraining each animal, the surgical procedure was performed. Ten milliliter of lidocaine (without vasoconstrictor) was injected into each spermatic cord and $5.0 \mathrm{~mL}$ along the surgical incision line of each testis. A $10 \mathrm{~cm}$ horizontal incision was made on the outside of the lower half of each side of the scrotum with a scalpel exposing the testicles. Another incision was made to remove the membranes covering the testicle until the testicle and epididymis were completely exposed. The spermatic cord was liberated from the tunica vaginalis and was ligated with two sterile nylon clamps ( $1 \mathrm{~mm}$ wide), placed transversally on the spermatic cord $2.0 \mathrm{~cm}$ apart. Kelly forceps were placed ventral to the second clamp and the spermatic cord was sectioned 2.0 $\mathrm{cm}$ below the ligature. The forceps were removed once no bleeding was observed. The procedure was repeated on the contralateral testis. The surgical wound was sprayed with a repellent and an antiseptic solution.

\section{Storage of the Epididymides}

Immediately after the orchiectomy, the bovine testes were individually packed and identified in plastic bags and maintained at $18-20^{\circ} \mathrm{C}$ for 6 to 30 $\mathrm{h}$ post-orchiectomy. The 20 epididymides were randomized allocated in five treatment groups according to the time post-orchiectomy: 6(G6), 12(G12), 18(G18), 24(G24) and 30(G30) hours, with a total of four epididymides per group.

\section{Semen Collection from the Caudal Epididymal}

When the specified storage time post-orchiectomy had elapsed, the testis-epididymis complex were washed with Ringer lactate solution preheated at $37^{\circ} \mathrm{C}$ to remove any vestige of blood and contaminants. The epididymis was dissected away from the testis and the spermatozoa were collected by the method of retrograde flushing as described by Martinez-Pastor et al. (2006) with modifications. Each cauda epididymis was washed with $20 \mathrm{~mL}$ of the diluent Botu-Turbo ${ }^{\mathrm{TM}}$ warmed at $37^{\circ} \mathrm{C}$ with its osmolarity specific for the bovine species $(20 \mathrm{~mL}$ of distilled water to $100 \mathrm{~mL}$ of medium). After the dissection of the vas deferens and the final portion of the epidermis duct, sperm wash medium was injected into the lumen of the vas deferens with the aid of a $0.7 \mathrm{~mm}$ hypodermic needle attached to a $3.0 \mathrm{~mL}$ syringe. The diluent was applied in the opposite direction of the normal flow of the spermatozoa. The diluted spermatozoa were deposited in a warmed recipient and placed in a water bath of $29^{\circ} \mathrm{C}$ for an hour for adaptation and stability. The same analyses were repeated for the semen collected by electro-ejaculation.

\section{Semen Refrigeration}

After collection and evaluation, the spermatozoa from epididymis and ejaculated were kept refrigerated in a transport container (Botutainer ${ }^{\mathrm{TM}}$, Botupharma, Botucatu, Brazil), which preserved the sample at a $5^{\circ} \mathrm{C}$, with a maximum refrigeration time of $48 \mathrm{~h}$. The spermatozoa from the right and left epididymis were pooled together, resulting in a single sample per animal, to which an equal volume of refrigerated medium (Botu-Turbo ${ }^{\mathrm{TM}}$, Botupharma, Botucatu, Brazil) (v/v) was added as done for the semen collected by electro-ejaculation method. Every $6 \mathrm{~h}$, the total motility of an aliquot of semen samples was evaluated until a minimum of $30 \%$ motility was attained.

\section{Statistical Analysis}

The data obtained in the experiment were initially submitted to the Shapiro-Wilk normality test. Data with distribution non-Gaussian, or the ordinal categorical variables used were the Kruskal-Wallis test (morphological deformed spermatozoa, acrosome defects, total motility and vigor) with the Dunn post-test. For continuous variables with Gaussian distribution (concentration/ml and total number of spermatozoa recovered), data were analyzed by ANOVA, with the Tukey-Karmer Multiple Comparisons test. For all the $P<0.05$ was considered significant. For the execution of descriptive and inferential statistics, the StatView software was used (SAS Institute Inc., Cary, NC, U.S.A). 


\section{RESULTS}

The electro-ejaculated semen (EES) demonstrated an average of $85 \%$ total motility, $5 \%$ vigor and $8.2 \%$ morphological defects in the spermatozoa of which only $2.6 \%$ comprised of acrosome defects (Table 1). Evaluation of the caudal epididymal spermatozoa showed no significant decline in sperm motility up to $24 \mathrm{~h}$, with only a significant decrease occurring in G30. The semen collected by electro-ejaculation method differed from its counterpart collected from the caudal epididymis at different hours for presenting higher motility, vigor and less morphological defects in spermatozoa $(\mathrm{p}<0.05)$ as shown in Table 1.
The sperm vigor demonstrated a little expressive reduction and the percentage of morphological defects in spermatozoa increased in proportion to the time for which the epididymides remained at room temperature. However none of the groups presented more than 30\% morphological defects. There was no significant difference between all the groups in relation to spermatozoa acrosome defects (Table 1).

In relation to the sperm concentration, the values reported varied greatly between the groups, having no correlation with the quantity of spermatozoa recovered. However there, was an association with the time of collection (Table 2).

Table 1 - Mean values and standard deviation of motility, vigor and morphological characteristics of the spermatozoa collected from the cauda epididymis (G6; G12; G18; G24; G30) and by electro-ejaculation method (EES) of Tabapuã bulls.

\begin{tabular}{cccccc}
$\begin{array}{c}\text { Sample } \\
(\mathbf{n = 4})\end{array}$ & Motility (\%) & Vigor (0-5) & $\begin{array}{c}\text { Morphological defects in } \\
\text { spermatozoa (\%) }\end{array}$ & $\begin{array}{c}\text { Sperm individual } \\
\text { defects (\%) }\end{array}$ & $\begin{array}{c}\text { Acrosome defects } \\
(\%)\end{array}$ \\
\cline { 1 - 3 } & & & $\mathrm{H}-\mathrm{MP}-\mathrm{T}$ & \\
EES* & $85 \pm 5.7^{\mathrm{a}}$ & $5 \pm 0^{\mathrm{a}}$ & $8.2 \pm 3.9^{\mathrm{a}}$ & $4-0,2-4$ & $2.6 \pm 2.1^{\mathrm{a}}$ \\
G6 & $67.5 \pm 11.9^{\mathrm{b}}$ & $5 \pm 0^{\mathrm{a}}$ & $9.5 \pm 3.1^{\mathrm{a}}$ & $2-0,5-7$ & $2 \pm 1.1^{\mathrm{a}}$ \\
G12 & $66.25 \pm 7.5^{\mathrm{b}}$ & $5 \pm 0^{\mathrm{a}}$ & $18 \pm 3.9^{\mathrm{b}}$ & $4-0-10$ & $2.25 \pm 3.2^{\mathrm{a}}$ \\
G18 & $67.5 \pm 2.8^{\mathrm{b}}$ & $4.5 \pm 1^{\mathrm{b}}$ & $21.25 \pm 6.1^{\mathrm{bc}}$ & $6-1,25-14$ & $3.75 \pm 2.9^{\mathrm{a}}$ \\
G24 & $58.75 \pm 8.5^{\mathrm{b}}$ & $4.7 \pm 0.5^{\mathrm{b}}$ & $19.5 \pm 3.1^{\mathrm{b}}$ & $5-1-13,5$ & $1.25 \pm 1.5^{\mathrm{a}}$ \\
G30 & $41.25 \pm 7.5^{\mathrm{c}}$ & $4 \pm 0^{\mathrm{c}}$ & $26.5 \pm 3.1^{\mathrm{c}}$ & $7-0,1-19,4$ & $3.5 \pm 0.5^{\mathrm{a}}$ \\
\hline F*
\end{tabular}

**EES $\mathrm{n}=10$

$\mathrm{H}$, head; MP, middle piece; $\mathrm{T}$, tail.

Different letters within the same column are significantly different $(\mathrm{P}<0.05)$

Table 2 - Mean values of the concentration in $\mathrm{ml}$, volume sample and total number of spermatozoa collected from the cauda epididymis (G6; G12; G18; G24; G30) and by electro-ejaculation method (EES) of Tabapuã bulls.

\begin{tabular}{cccc}
\hline Sample $(\mathbf{n}=\mathbf{4})$ & Concentration $\left(\mathbf{1 0} \mathbf{6}^{\mathbf{6}} \mathbf{m l}\right)$ & Volume sample $(\mathbf{m l})$ & Total number of \\
\hline EES spermatozoa recovered $\left(\mathbf{1 0}^{\mathbf{6}}\right)$ \\
G6 & $568.5^{\mathrm{a}}$ & 5.5 & $3,155.1^{\mathrm{a}}$ \\
G12 & $189.375^{\mathrm{b}}$ & 20 & $3,787.5^{\mathrm{a}}$ \\
G18 & $426.875^{\mathrm{a}}$ & 20 & $8,537.5^{\mathrm{c}}$ \\
G24 & $321.25^{\mathrm{a}}$ & 20 & $6,425.0^{\mathrm{bc}}$ \\
G30 & $181.875^{\mathrm{b}}$ & 20 & $3,637.5^{\mathrm{ab}}$ \\
\hline
\end{tabular}

$*$ EES $n=10$

Different letters within the same column are significantly different $(\mathrm{P}<0.05)$

When evaluating the groups G12 and G18 the number of recovery spermatozoa was high $(\mathrm{p}<0.05)$ than others. The highest average of 426,875 million spermatozoa per $\mathrm{ml}$ was observed in G12 and an average of 8.53 billion spermatozoa recovered from the cauda of only one of the epididymis. Evaluation of the total concentration of epididymal sperm that was pooled by the samples from the right and left epididymis, showed the average number of spermatozoa recovered was $9.58 \pm 5$ billions, being higher than the average score of $3.21 \pm 2.4$ billion spermatozoa of the semen collected via electro-ejaculation of the same animals $(\mathrm{p}<0.05)$.

Spermatozoa cooled at $5^{\circ} \mathrm{C}$ remained viable for 15 to $40.8 \mathrm{~h}$ post-collection depending on the storage 
time (Table 3). The semen collected via electroejaculation had an average durability of $40.8 \mathrm{~h}$ (total motility $\geq 30 \%$ ) and for the epididymal spermatozoa the groups varied between 15 to $36 \mathrm{~h}$. The G24 demonstrated an average cooling resistance of $36 \mathrm{~h}$ along with $24 \mathrm{~h}$ in the epididymis, totaling $60 \mathrm{~h}$ or 2.5 days postorchiectomy that maintained good sperm motility for future use. The least resistant to cooling at $5^{\circ} \mathrm{C}$ was the group G30 (15 h).

Table 3 - Time at room temperature, average and standard deviation of resistance time at $5^{\circ} \mathrm{C}$ (minimum of $30 \%$ motility) and total time after orquiectomy of the spermatozoa collected from the cauda epididymis (G6; G12; G18; G24; G30) and by electro-ejaculation method (EES) from Tabapuã bulls.

\begin{tabular}{cccc}
\hline $\begin{array}{c}\text { Specimen } \\
(\mathbf{n = 2})\end{array}$ & $\begin{array}{c}\text { Time at } \mathbf{1 8 - 2 0} \mathbf{}^{\circ} \mathbf{C} \\
\text { (hours) }\end{array}$ & $\begin{array}{c}\text { Resistance time of spermatozoa at } \mathbf{5}^{\circ} \mathbf{C} \\
\text { (hours) }\end{array}$ & $\begin{array}{c}\text { Total time after orquiectomy } \\
\text { (hours) }\end{array}$ \\
\hline EES* & 0 & $40.8 \pm 22.2^{\mathrm{a}}$ & - \\
G6 & 6 & $27 \pm 21.2^{\mathrm{a}}$ & 33 \\
G12 & 12 & $21 \pm 4.4^{\mathrm{a}}$ & 33 \\
G18 & 18 & $30 \pm 8.4^{\mathrm{a}}$ & 48 \\
G24 & 24 & $36 \pm 25.4^{\mathrm{a}}$ & 60 \\
G30 & 30 & $15 \pm 4.2^{\mathrm{b}}$ & 45 \\
\hline
\end{tabular}

$*$ EES $\mathrm{n}=10$

Values followed by different letters in the same column are significantly different $(\mathrm{p}<0.05)$

\section{DISCUSSION}

Recent studies have demonstrated that epididymal spermatozoa has been viable for a determined time after the death of the animal, however this varies according to climatic conditions and temperature (Tittarelli et al. 2006). In this study, sperm motility was the parameter most affected by time after orquiectomy (Table 1). Previous studies in different species ( $\mathrm{Yu}$ and Leibo 2002; Kaabi et al. 2003; Martinez-Pastor et al. 2005; Muradás et al. 2006) have reported that the motility of epididymal spermatozoa was the first parameter to be affected by post-mortem, followed by morphological alterations. This was due to the fact that the longer the post-mortem time, the higher the rate of tissue decomposition and degeneration of motile spermatozoa (Songsasen et al. 1998). However, the group G30 even though showing a significant decline $(\mathrm{p}<0.05)$ in comparison to the other groups, still possessed a considerable quantity $(41.25 \%)$ of motile spermatozoa (Table 1 ) revealing a promising results that even after $30 \mathrm{~h}$ of castration, it was still possible to recover a good amount of motile spermatozoa from the epididymis of the bulls under conditions of room temperature.

The spermatozoa collected from the cauda epididymides of the bulls showed no significant decrease in sperm motility only until $24 \mathrm{~h}$ after storage at room temperature, as described in sheep (Kaabi et al. 2003) and stallions (Muradás et al.
2006). Other studies have reported that under refrigeration storage of epididymis (Soler et al. 2005; Martins et al. 2009), a significant decline occurred only after $48 \mathrm{~h}$ when storage was at $5^{\circ} \mathrm{C}$, showing that transport the testis after orchiectomy to laboratory at $5^{\circ} \mathrm{C}$ was better to maintain sperm viability than at room temperature, but in most cases it might not a viable alternative, which demonstrated the importance of knowing how to manage under such conditions.

The results obtained in this study have shown that there were differences between the sperm characteristics of epididymal and ejaculated sperm of the bulls as described by Silva et al. (2003), principally in sperm motility which was lower in epididymal spermatozoa, mainly due to the effects of time and lack of seminal plasma on these samples.

As shown in Table 1, sperm vigor decreased $18 \mathrm{~h}$ after storage; however, remained constant until 30 $\mathrm{h}$ after storage after which a significant decrease was observed. As the vigor was directly related to the motility, showing that the time after castration also affected this parameter. However, these values were considered satisfactory for this species. There was an increase in spermatozoa morphological alterations due to the permanence time of the spermatozoa in the epididymis, being higher than that in the EES group. The presence of distal cytoplasmic droplets was the defect with the highest frequency (Table1), which was in accordance with other studies involving bull 
epididymal sperm (Silva et al. 2003; Martins et al. 2009). The presence of distal cytoplasmic droplets was considered normal for spermatozoa recovered directly from the bull's epididymides and correlating the sperm individual defects with the storage period with the morphological aspect was the sperm tail. The values obtained in all the groups were lower than $30 \%$, that was the maximum value recommended for the utilization of bull semen (CBRA 1998) favoring the use of spermatozoa. In all the groups, there was no higher percentage of loss in acrosome integrity and there was no significant difference between the groups for this parameter ensuring good quality to sperm (Table1). A study in stallions (Muradás et al. 2006) reported that the defects in the spermatozoa acrosome did not differ between the epididymal and ejaculated sperm when maintained at a room temperature. This occurred because under these conditions, there was no risk of injury due to freezing, osmotic stress, oxidative stress and thermal shock responsible for cause lesions to the acrosome membrane (Crister and Mobraten 2000). The average concentration obtained per epididymis between the groups (Tab. 2) showed no direct correlation with time; instead there was an association with the collection efficiency and the size of the testes and epididymides of the animals. Bulls randomly allocated in G12 were older bulls and as such possessed a higher scrotal circumference, which reflected in superior sperm production (Silva et al. 2002). The mean concentration obtained were similar to those found by Turri et al. (2011) that utilized the retrograde flushing technique, and were higher than described by Martins et al. (2009) in the recovery of spermatozoa through incisions made in the caudal epididymis. In all the groups the concentration of spermatozoa recovered was satisfactory allowing the widespread use of genetic material.

The predominant effect of spermatozoa storage at $5^{\circ} \mathrm{C}$ after the collection was a reduction in the metabolic rate of the spermatozoa, which aided to prolong their survival time (Vishwanath and Shannon 2000). This was an important tool for the sperm manipulation after collection. Table 3 showed that the time required for the decline in sperm motility varied between groups. Spermatozoa were not adapted to survive at low temperatures; however, they had variable responses at cooling depending on the individual and species (Holt 2000). The G24 group had higher durability than the other epididymis groups, possibly due to the individual effect of one bull that produced spermatozoa resistant to cooling (Watson 2000). This variation individual has been reported in several species (Hernandéz et al. 2007; Aurich 2008; Medrano et al. 2010), and can be called as the 'bull effect' in cattle.

These results supported the use of the procedures described on this study in cases of sudden death from a breeder of high genetic value when carcass was exposed to a temperature around $18-20^{\circ} \mathrm{C}$.

\section{CONCLUSION}

It was concluded that it was possible to recover viable spermatozoa with $41.25 \%$ of motility from the cauda epididymis stored at room temperature at $18-20^{\circ} \mathrm{C}$ for $30 \mathrm{~h}$ in the bulls after orquiectomy. The epididymal spermatozoa differed from the ejaculated spermatozoa, which represented higher motility, vigor and less amount of total morphological defects $(\mathrm{p}<0.05)$; the acrosome defects did not differ. The cooling $\left(5^{\circ} \mathrm{C}\right)$ of the sperm was a viable alternative for the temporary preservation of gametes to maintain good motility up to $36 \mathrm{~h}$ for spermatozoa collected from the caudal epididymis and $40.8 \mathrm{~h}$ for those collected by electro-ejaculation method.

\section{REFERENCES}

Aurich C. Recent advances in cooled-semen technology. Anim Reprod Sci. 2008; 107(3-4): 268275.

Blom E. The ultrastructure of some characteristic sperm defect and a proposal for a new classification of bull spermiogram. Nord Vet Med. 1973; 25(7-8): 383-391.

COLÉGIO BRASILEIRO DE REPRODUÇÃO ANIMAL - CBRA. Manual para exame andrológico e avaliação de sêmen animal, 2nd ed. Belo Horizonte: Colégio Brasileiro de Reprodução Animal; 1998.

Costa PM, Martins CF, Franco VO, Rezende LOF, Sereno JRB, Campos HCF. Birth of normal calves after artificial insemination using cryopreserved spermatozoa obtained from refrigerated epididymides of death bovin. Cienc Rural. 2011; 4(5): 869-874.

Crister JK, Mobraten LE. Cryopreservation of murine spermatozoa. ILAR j. 2000; 41(4): 197-206.

Garde J, Ortiz N, Garcia A, Gallego L, Landete CT, Lopez A. Post-mortem assessment of sperm characteristics of the red deer during the breeding season. Arch Androl. 1998; 41(3): 195-202. 
Hernández M, Roca J, Gil MA, Vázquez JM, Martínez EA. Adjustments on the cryopreservation conditions reduce the incidence of boar ejaculates with poor sperm freezability. Theriogenol. 2007; 67: 14361445.

Holt WV. Basic aspects of frozen storage of semen. Anim Reprod Sci. 2000; 62(1-3): 3-22.

Jones R. Sperm survival versus degradation in the mammalian epididymis: A hypothesis. Biol Reprod. 2004; 71(5): 1405-1411.

Kaabi M, Paz P, Alvarez M, Anel E, Boixo JC, Rouissi $\mathrm{H}$, Herraez P, Anel L. Effects of epididymis handling conditions on the quality of ram spermatozoa recovered post-mortem. Theriogenol. 2003; 60(7): 1249-1259.

Martinez-Pastor F, Guerra C, Kaabi M, Diaz AR, Anel E, Herraez P, Anel L. Decay of sperm obtained from epididymes of wild ruminants depending on postmortem time. Theriogenol. 2005; 63(1): 24-40.

Martinez-Pastor F, Garcia-Macias V, Alvarez M, Chamorro P, Herraez P, de Paz P, Anel L. Comparison of two methods for obtaining spermatozoa from the cauda epididymis of Iberian red deer. Theriogenol. 2006; 65(3): 471-485.

Martins CF, Driessen K, Melo Costa P, Carvalho-Neto JO, De Sousa RV, Rumpf R, Dodec MN. Recovery, cryopreservation and fertilization potential of bovine spermatozoa obtained from epididymides stored at $5{ }^{\circ} \mathrm{C}$ by different periods of time. Anim Reprod Sci. 2009; 116(1-2): 50-57.

Martins CF, Rumpf R, Pereira DC, Dode MN. Cryopreservation of epididymal bovine spermatozoa from dead animals and its uses in vitro embryo production. Anim Reprod Sci. 2007; 101(3-4): 326331.

Medrano A, Terrazas A, Soto R. Principles and perspectives for the conservation of goat buck spermatozoa. Small Ruminat Res. 2010; 89: 140-143.

Monteiro GA, Papa FO, Zahn FS, Dellaqua Jr JA, Melo $\mathrm{CM}$, Maziero RRD, et al. Cryopreservation and fertility of ejaculated and epididymal stallion sperm. Anim Reprod Sci. 2011; 127: 197-201.

Muradás PR, Weiss RR, Kozicki LE, Granemann LC, Santos IW, Pimpão CT. Some viability parameters from equine spermatozoa harvested by artificial vagina and by epididymal tail washing. Arch Vet Sci. 2006; 11(3): 69-74.

Ringleb J, Waurich R, Wibbelt G, Streich WJ, Jewgenow $\mathrm{K}$ Prolonged storage of epididymal spermatozoa does not affect their capacity to fertilise in vitro-matured domestic cat (Felis catus) oocytes when using ICSI. Reprod Fertil Dev. 2011; 23(6) 818-825.
Santiago-Moreno J, Toledano-Díaz A, Pulido-Pastor A, Gómez-Brunet A, López-Sebastián A. Birth of live Spanish ibex (Capra pyrenaica hispanica) derived from artificial insemination with epididymal spermatozoa retrieved after death. Theriogenol. 2006; 66(2): 283-291.

Silva AEDF, Dias AL, Unanian MM, Freitas AR, Bloch CJ. Peptides Content and Morphophisiological Evaluation of Epididymis and Ejaculated Sperm in Bovin. Rev Bras Zootec. 2003; 32(6): 1890-1900.

Silva AEDF, Unanian MM, Cordeiro CMT, De Freitas AR. Relationship of Scrotal Circumference and the Semen Quality Parameters in Nellore Purebred Bulls. Rev Bras Zootec. 2002; 31(3): 1157-1165.

Soler AJ, Esteso MC, Fernández-Santos MR, Garde JJ. Characteristics of Iberian red deer (Cervus elaphus hispanicus) spermatozoa cryopreserved after storage at $5^{\circ} \mathrm{C}$ in the epididymis for several days. Theriogenol. 2005; 64(7): 1503-1517.

Songsasen N, Tong J, Leibo SP. Birth of live mice derived by in vitro fertilization with spermatozoa retrieved up to twenty-four hours after death. $J$ Exp Zool. 1998; 280(2): 189-196.

Tittarelli C, Savignone CA, Arnaudín E, stornelli MC, Stornelli MA, De La Sota RL. Effect of storage media and storage time on survival of spermatozoa recovered from canine and feline epididymides. Theriogenol. 2006; 66(6-7): 1637-1640.

Toyonaga M, Kaihara A, Tsutsui T. The Quality of cryopreserved sperm collected from feline caudal epididymides stored at room temperature. J Vet Med Sci. 2011; 73(10): 1395-1398.

Turri F, Madeddu M, Gliozzi TM, Gandini G, Pizzi F. Influence of recovery methods and extenders on bull epididymal spermatozoa quality. Reprod Domest Anim. [internet] 2011 jun [cited 2012 jan 20] [about 6p.]. Available from: http: http://onlinelibrary.wiley. com/doi/10.1111/j.1439-0531.2011.01948.x/full

Vishwanath R, Shannon P. Storage of bovine semen in liquid and frozen state. Anim Reprod Sci. 2000; 62(1-3): 23-53.

Watson PF. The causes of reduced fertility with criopreserved semen. Anim Reprod Sci. 2000; 60-61: 481-492.

Weiss RR, Muradás PR, Graneman LC, Meira C. Freezing sperm from cauda epididymis of castrated stallions. Anim Reprod Sci. 2008; 107(3-4): 302-360.

Yu I, Leibo SP. Recovery of motile, membrane-intact spermatozoa from canine epididymides store for 8 days at $4^{\circ} \mathrm{C}$. Theriogenol. 2002; 57(3): 1179-1190. 
